\title{
La amistad cívica en Aristóteles: concordia y fraternidad*
}

\section{Civic Friendship in Aristotle: Concord and Fraternity}

\author{
Oriol FARRÉS JUSTE \\ Universidad Autónoma de Barcelona
}

Recibido: 17/07/2014

Aceptado: 15/09/2014

\section{Resumen}

El artículo muestra la importancia de la amistad en el contexto de la filosofía política aristotélica. Esta importancia se verifica en su peso específico en comparación con la justicia, puesto que Aristóteles mismo sostiene que la amistad cívica es incluso un objetivo superior al de la búsqueda de la justicia. En concreto, el artículo se centra en la función de la concordia, como tipo especial de amistad cívica, en términos de conservación de la unidad y estabilidad de la polis. Para captar su significación, se plantea el papel de la concordia como complemento a la condición política del ser humano. La concordia es necesaria a la luz de la tendencia a la lucha entre las partes de la ciudad, entre el demos y los oligarcas. Puesto que esta lucha pone en peligro la continuidad de la polis, la concordia entre ciudadanos se convierte en un antecedente privilegiado del principio de fraternidad republicana, el cual todavía no ha gozado de una atención suficiente en el campo de la historia de la filosofía política.

Palabras clave: Amistad, concordia, democracia, fraternidad, lucha de clases, republicanismo.

\footnotetext{
* Este artículo es resultado del proyecto de investigación FFI2012-33370, titulado Fraternidad, Justicia y Democracia, y financiado por el Ministerio de Economía y Competitividad (España)
} 


\begin{abstract}
The article shows the importance of friendship in the context of Aristotelian political philosophy. This importance is verified in its specific weight compared with justice. As it is known, Aristotle argues that the pursuit of friendship outranks the pursuit of justice in the polis. Particularly, the article focuses on the role of concord, as a special type of civic friendship, in terms of preserving the unity and stability of the polis. To grasp its significance, we have to consider the role of concord as a supplement of the political condition of the human being. Concord is necessary in the light of the trend to the struggle between the parts of the city, between the demos and the oligarchs. Since this fight endangers the continuity of the polis, concord among citizens becomes a privileged background of early republican fraternity, which has not enjoyed sufficient attention in the field of history of political philosophy.
\end{abstract}

Keywords: Class struggle, concord, democracy, fraternity, friendship, republicanism.

\title{
1. Introducción
}

La amistad también parece mantener unidas las ciudades, y los legisladores se afanan más por ella que por la justicia. En efecto, la concordia parece ser algo semejante a la amistad, y a ella aspiran sobre todo, y en cambio procuran principalmente expulsar la discordia, que es enemistad. Y cuando los hombres son amigos, ninguna necesidad hay de justicia, pero, aun siendo justos, sí necesitan de la amistad, y parece que son los justos los que son más capaces de amistad. ${ }^{1}$

El problema de la amistad cívica en Aristóteles: este es el tema que nos ocupará en las siguientes páginas. Para empezar, es útil hacer una precisión terminológica. Decimos "amistad cívica" incardinados en la tradición anglosajona de la expresión "civic friendship" que traduce la philía politiké2 griega. El término "amistad

\footnotetext{
1 Ética Nicomáquea, 1155a 20-30.

2 "Amistad civil" podría ser otra propuesta terminológica posible. El término "politikề" incluye las connotaciones de "civil" (propio de la ciudad o civilización), "cívico" (cualidad de cortés o civilidad) y "político" (en términos de participación en el espacio público). Según Aristóteles, es la amistad que se desarrolla en el contexto de la ciudad, y en la cual no se precisa una relación de proximidad y reciprocidad tan fuerte como con la amistad basada en la virtud o el bien, por ejemplo.

3 Una de las formas modernas que toma la amistad cívica es precisamente la idea de fraternidad (Furet y Ozouf). Pero el origen etimológico de "fraternidad" remite a la "phratría", de orientación conservadora -siendo una comunidad ancestral (Fine, Lambert)- y posiblemente ligada al concepto de facción, que en realidad es lo opuesto a la idea política de fraternidad civil.
} 
política", que pudiera parecer más próximo al original, tiene unas connotaciones demasiado partidistas que entorpecen, a nuestro entender, la comprensión del cometido y función de este tipo de amistad en la argumentación aristotélica. No se trata de una "amistad política" entendida como camaradería o facción ${ }^{3}$ (como las sètte que Maquiavelo critica con dureza, pongamos por caso), sino precisamente del problema de la unión o cohesión de la totalidad de la ciudad, de la polis (del interés común contrapuesto al de las partes de la ciudad). La noción de "amistad política", además, podría llegar a incorporar una carga de clientelismo político (de relaciones clientelares, cliente-patrono) que, por cierto, no solo sería inadecuada, sino también anacrónica con respecto al contexto que vamos a examinar.

Pues bien, la amistad cívica, si funciona, consigue reunir la comunidad política (o sociedad civil) ${ }^{4}$, hasta el punto de que "los legisladores", como dice Aristóteles en el fragmento citado, "se afanan más por ella que por la justicia". Aquí parece que la tendencia natural en el ser humano como "animal político" no es suficiente para alcanzar la unidad y estabilidad de las ciudades. La cualidad "política" del animal humano no se puede identificar simplemente con la amistad cívica; por tanto, lo que sucede más bien es que este tipo de amistad se convierte en un complemento a la condición política de los hombres. La pregunta básica que nos debemos formular ahora es por qué razón es necesario este tipo de amistad cívica que Aristóteles denomina "concordia" (homónoia). Esto es, ¿de dónde nace la exigencia de mantener la unidad de la ciudad una vez se ha reconocido el potencial gregario-político humano? ¿Por qué ello no es suficiente? La respuesta a esta cuestión, como no podía ser de otro modo, radica en otra tendencia opuesta a la concordia, que en el fragmento citado es referida como "discordia". Es el problema de la discordia, conflicto pugnaz o lucha intestina (stásis) ${ }^{5}$ en el seno de la comunidad política lo que precisa el correctivo de la amistad cívica que se postula como superior a la justicia misma en el orden de prioridades de los legisladores antiguos (siendo, claro está, la concordia un tipo especial de amistad cívica).

Dicho de otra manera, los dos términos básicos aquí son, por un lado, la constatación de la condición política del ser humano y, por el otro, la condición combativa del ciudadano (y por lo tanto, también política) en el marco de la ciudad. Es más: estos dos términos son, como veremos más adelante, las dos caras de una misma moneda. Y en todo caso, la concordia es una propuesta teórica aplicable ante esta contradicción.

\footnotetext{
4 Aquí aparece otro problema terminológico: la koinōnía politikế se puede traducir de ambas maneras: como "sociedad civil" o "comunidad política", siguiendo también la expresión anglosajona "political community". En el contexto antiguo, no existía la separación moderna entre Estado y sociedad civil. 5 El término stásis tiene dos significados: uno estático ("posición" o "situación") y otro dinámico ("erguirse", "ponerse en pie"). La idea de stásis que prima en el contexto político es evidentemente dinámica: remite a "alzarse", "levantarse" o "sublevarse". Alude, pues, al "alzamiento", expresión que tiene, por cierto, unas claras connotaciones en la historia contemporánea española.
} 


\section{Contextualización del problema}

Para captar la situación de partida en Aristóteles, debemos remontarnos a la condición social, civil o política del hombre (aquí estos tres términos son sinónimos). "El hombre es un ser social y dispuesto por la naturaleza a vivir con otros" (E.N., 1169b17) o "el hombre es un ser cívico por naturaleza" (Política, 1253a9). La condición política y lingüística, como se dice y repite, es lo que garantiza la posibilidad de una vida buena (Pol., 1253a12; E.N., 1170b11). Sabemos, también, que Aristóteles no menosprecia la vida por sí misma, al margen de la "buena vida" que solo se puede encontrar dentro de los límites de la polis. Hay, dice Aristóteles, un bien intrínseco al mero vivir:

Se ha dicho en las primeras exposiciones, en las que se ha definido la administración doméstica y la autoridad del amo, que el hombre es por definición un animal político y, por eso, aun sin tener necesidad de ayuda recíproca, los hombres tienden a la convivencia. No obstante, también la utilidad común los une, en la medida en que les impulsa la participación en el bienestar. Éste es, efectivamente, el fin principal, tanto para todos en común como aisladamente. Pero también se reúnen por el mero vivir, y constituyen la comunidad política. Pues quizá en el mero hecho de vivir hay una cierta parte del bien, si en la vida no predominan en exceso las penalidades. Es evidente que la mayoría de los hombres soportan muchos sufrimientos en su vivo deseo de vivir, como si en el vivir hubiera una cierta felicidad y dulzura natural. ${ }^{6}$

Si vivir ya es (o suele ser) un bien por sí mismo, todavía habrá, por necesidad, un bien mayor en vivir bien. Aquí es necesario destacar dos aspectos: en primer lugar, la convivencia política se podría haber realizado únicamente por el mero hecho de vivir (o sobrevivir); y en segundo lugar, no toda forma de convivencia, como se explica en el primer libro de la Política, es propiamente política, por más que la ciudad sea el bien al que tienden (teleológicamente) las demás organizaciones de tipo menor, como las familias o las aldeas. La política se abre precisamente sobre la cuestión de qué es "vivir bien" a partir del "vivir con" (convivencia), esto es, de cuál es su sentido. "La ciudad es la comunidad, procedente de varias aldeas $(k \bar{o} m \bar{e})$, perfecta, ya que posee, para decirlo de una vez, la conclusión de la autosuficiencia total, y que tiene su origen en la urgencia del vivir, pero subsiste para el vivir bien." (Pol., 1252b8). Y es en este punto donde cabe citar un importante pasaje de la Política de Aristóteles:

En todos existe, por naturaleza, la tendencia hacia tal comunidad; pero el primero que la estableció fue causante de los mayores beneficios. Pues así como el hombre perfecto es el mejor de los animales, así también, apartado de la ley y de la justicia, es el peor de todos. ${ }^{7}$

\footnotetext{
6 Pol., 1278b 23-31.
}

7 Pol., 1253a 30-35. 
Este fragmento es muy relevante porque clarifica que la tendencia a la ciudad no implica por sí misma la existencia de la ciudad8. Aristóteles habla del "primero que la estableció". Sin duda, la alusión es mítica (remite a los fundadores de ciudades o estados). Pero en su formulación, se pone de manifiesto que la política no es un derivado automático de la naturaleza humana, sino que tiene que ser realizada por alguien, tiene que ser efectuada y, por tanto, se debe a un esfuerzo suplementario que, como tal, va más allá de la conservación de lo dado. La actualización de la potencialidad política es contingente; podría no haber acontecido. Hay un tipo de acción que funda los criterios a partir de los cuales incluso esta acción misma puede ser juzgada: el fundador de la ciudad es el "causante de los mayores beneficios". Establecer la ciudad, hacerla9, es lo mismo que posibilitar el campo a partir del cual aparece el valor: el hombre, en efecto, puede ser el mejor y el peor de los animales, como dice Aristóteles (Pol., 1253a15). Más todavía, la oportunidad de ser el mejor de los animales y regirse por la justicia en la ciudad es al mismo tiempo un riesgo: el riesgo de convertirse en el peor de los animales y regirse por la injusticia y la tiranía. O dicho de otra manera, la posibilidad de la construcción política implica, como su reverso necesario, la posibilidad de su destrucción, ya sea por la vía de la dominación o por la vía de la desaparición de los lazos ciudadanos. La cuestión del valor normativo, entonces, aparece en la comunidad donde la justicia se tematiza (y se problematiza), y este lugar es la ciudad. Todo sucede como en una apuesta, desde la política, sobre la propia condición humana de la convivencia. A primera vista, se trata de la tesis de la sociogénesis de la moral, si bien quizá sería más exacto decir "politogénesis" (ya que su génesis parece estar en la polis, la ciudad). No es la mera asociación humana con vistas a la supervivencia lo que produciría el juicio ético (como cualificación del animal humano), sino un tipo de asociación determinada que se denomina "política". Se podría afirmar, en consecuencia, que la ética se revela en el contexto ciudadano.

Pero no es exactamente así. La ética, al mismo tiempo, tampoco se deriva totalmente de la base de la justicia política en la ciudad o polis. Existe una franja intermedia: "Habrá, pues, una cierta comunidad y una cierta justicia, aun cuando no exista la ciudad, pues la familia es una amistad." (Ética Eudemia, 1242a 25-30) Y esta franja intermedia donde hay una "cierta" justicia sin leyes y una "cierta" comunidad sin ciudad solo tiene su origen en lo que Aristóteles llama "amistad" (philía)

\footnotetext{
${ }^{8}$ M. Zingano repara en esta cuestión en su análisis de la justicia en Aristóteles: "However, being political by nature does not mean that human beings come to live in cities as a biological upshot of their instincts. It means instead that nature endows human beings with impulses that lead them to live in groups, and that human beings have the ability to organize those groups into cities, in so far as human beings are endowed with perception of what is harmful or beneficial, and hence of what is just or unjust." (Zingano, 2013, p. 201)

9 Hannah Arendt en The Human Condition distingue la acción técnica o poiética del legislador de las acciones praxiales que luego tendrán lugar en la esfera de la política por él establecida.
} 
en el ámbito familiar del ôkkos. Este punto tiene una importancia fundamental: la ética aparece junto a la amistad, acompañándola 10 . Por tanto, ya hay algo previo a las instituciones políticas que cualifica las relaciones humanas ${ }^{11}$. Ello no debe entenderse como un elemento que sutura la diferencia entre lo natural (esfera familiar) y lo artificial (esfera política), como si la ética estuviese naturalizada por el impulso de la amistad que sería innato y, en consecuencia, natural. Todo cae dentro del ámbito de lo natural, tanto la familia como la ciudad; pues esta última también es, según Aristóteles, una comunidad natural en la medida en que es la verdad (o la realización teleológica) del hecho comunitario patente en las agrupaciones más originarias, como las familias y aldeas; y más aún, es el marco a partir del cual se logrará, agregándolas, la autosuficiencia. La ética surge, entonces, en el ámbito fundado por la amistad (que no solo incumbe a los animales humanos, sino también a algunos otros, [E.E., 1236b5]) y este ámbito es previo a la ciudad (esto es, previo a la política misma). De ahí el carácter estratégico del estudio ético-político de la amistad en Aristóteles. Vemos que precede a lo humano, como sentimiento animal de afecto, pero también vemos que puede completar la estructura jurídica de la polis, coronación de lo humano, sin la cual, además, siempre será insuficiente.

La amistad es anterior a la política, pero la polis no es posible sin la amistad (así que la amistad continúa operando en la esfera política). Por otro lado, la ética precede a la política, pero no se agota en la política (no hay substitución o eticidad hegeliana), sino que es algo que también debe vivir en ella aunque no le pertenezca absolutamente. A pesar de que el criterio de los mejores regímenes políticos parta, como es evidente, de ciertos elementos éticos: el buen ciudadano, en el mejor régimen, es también un ciudadano bueno, hay una dimensión en la cual la ética (y concretamente, en la amistad entre los filósofos) trasciende propiamente los quehaceres políticos $(E . N ., \mathrm{X})$ en la forma de vida contemplativa. En esta lógica, nunca

\footnotetext{
10 "Pues la amistad es una virtud o algo acompañado de virtud y, además, es lo más necesario para la vida." (E.N., 1155a 1-5)

11 Paralelamente a la amistad, la justicia también recorre este circuito que va de lo prepolítico a lo político. "In Aristotelian teleological thought, associations of individuals in couples and households do not stand on their own, but represent stages toward, or are parts of, the perfect community, the polis. As communities, they have justice of a kind; each just relation takes on the metaphysical status of the corresponding community, which is a part of the polis. As justices of a sort, they are no mere metaphor; on the contrary, their resemblance reflects their teleological dependence on political justice, in so far as the corresponding communities are parts of the polis." (Zingano, 2013, p. 206) Ahora bien, esta "justicia prepolítica" no se identifica con la justicia natural sin más. La justicia natural en Aristóteles no debe entenderse como opuesta a la justicia política, sino a la justicia convencional, siendo estas dos, la convencional y la natural, partes de la justicia política (Zingano, 2013, p. 212). No hay, pues, ni desde la óptica de la amistad ni desde la óptica de la justicia, un "estado de naturaleza" independiente del "estado civil". Esto implicaría proyectar anacrónicamente el paradigma de la filosofía política moderna contractualista en el contexto aristotélico. Para una discusión sobre la justicia natural en Aristóteles, véase también Horn y Miller.
} 
hay cancelación de los estadios anteriores. Lo que hay, en todo caso, es una superabundancia que constituye una realidad emergente. El deseo de convivencia es lo que lleva aparejado, sin reducirse a él, un excedente que luego posibilita explicitaciones de la justicia en el campo de la política (en forma de valor). Y esto es así por una razón que podríamos tildar de sentido común: "Y puesto que es deseable vivir bien y en compañía, es evidente que la convivencia, unida incluso a un bien más pequeño, es, de algún modo, más deseable que disfrutar separadamente de un bien mayor." (E.E., 1246a5). La sutileza de este fragmento de la ética aristotélica no nos debería pasar inadvertida. Aquí aún no se da una argumentación normativa que justifique la renuncia a un bien mayor por la obligación hacia los demás -Aristóteles no argumenta desde el paradigma de un pago (un tributo) a la ciudad para obtener la recompensa de la vida en el resguardo de la comunidad (seguridad). Aquí se trata únicamente de constatar un deseo: un bien mayor gozado separadamente, fuera de la comunidad, es menos deseable que un bien menor disfrutado en compañía. Luego, la compañía se puede revelar como un bien: es algo vinculado a "vivir bien" ("vivir bien y en compañía", se puede leer, y más adelante se rebla: "convivencia"). Todo esto debe interpretarse como el cómputo de una cantidad indeterminada (un excedente) de bien que cualificará luego las relaciones entre los participantes en los asuntos de la ciudad. Esta es la parte constructiva de la convivencia que encamina los ciudadanos hacia la buena vida.

En resumen, la vida por sí misma puede ser un bien, pero la buena vida es un bien todavía mayor; y en cualquier caso, para Aristóteles es inimaginable una vida que no sea disfrutada en compañía (lejos están aún las figuras del eremita solitario o las robinsonadas modernas). La condición política del animal humano parte, pues, de una forma rudimentaria de amistad que Aristóteles atribuye a las esferas anteriores, las propias de las familias y las aldeas. Pero esta amistad todavía no es la concordia o amistad cívica que facilita la unidad de la ciudad.

Hemos visto que la fundación de la ciudad acarreaba una cuestión sobre el vivir bien, es decir, una cuestión de valor. Se podría decir que la política explicita la posibilidad de deliberar sobre este bien del vivir bien. De hecho, Susan Bickford ${ }^{12}$ sostiene que no es propiamente la amistad lo que en Aristóteles funciona como elemento cohesionador de la ciudad, sino la deliberación y, en concreto, lo que ella denomina "atención" a las razones de los demás. Con todo, esto es confundir dos

\footnotetext{
12 "I argue that Aristotle's analysis of deliberation demonstrates the centrality of (often deep) conflict in political interaction, and has two important contributions to make to our contemporary understanding of politics. First, Aristotle's analysis of deliberation forces us to extend our understanding of adversary procedures, for it is precisely when conflict is present that communicative interaction among citizens is most necessary. Secondly, this conception of political practice does not require the bonds of civic friendship underneath conflict, nor a strong sense of shared interests. What governs and makes possible such adversarial communicative interaction is not, for Aristotle, friendship or concord, but rather a quality of attention inherent in the very practice of deliberation." (Bickford, 1996, p. 399)
} 
instancias clave en esta cuestión: una es la amistad cívica, que es la que permite la deliberación en común, y la otra es la concordia, que se alcanza cuando las conclusiones de la deliberación son ampliamente compartidas por todas las partes de la ciudad y aúna sus intereses. Tampoco se debe confundir la amistad cívica con la amistad ética, virtuosa y entre iguales. Sea como sea, lo cierto es que, en Aristóteles, el uso de la palabra, que posibilita la deliberación, es clave en la sociabilidad humana:

La razón por la que el hombre es un ser social, más que cualquier abeja y que cualquier animal gregario, es evidente: la naturaleza, como decimos, no hace nada en vano, y el hombre es el único animal que tiene la palabra. Pues la voz es signo del dolor y del placer, y por eso la poseen los demás animales, porque su naturaleza llega hasta tener sensación del dolor y del placer e indicársela unos a otros. Pero la palabra es para manifestar lo conveniente y lo perjudicial, así como lo justo y lo injusto. Y esto es lo propio del hombre frente a los otros animales: poseer, él sólo, el sentido del bien y del mal, de lo justo y de lo injusto, y de los demás valores, y la participación comunitaria en estas cosas constituye la casa y la ciudad. 13

Puesto que hay palabra, hay deliberación sobre los valores que, más allá de los afectos, se ponen en juego. Y aquí es donde aparecen, sin duda, las distintas propuestas políticas, los intereses y las luchas que conforman la arena política. Y es que para el surgimiento de la concordia, hace falta pasar por otro factor de vital importancia en la formación de la ciudad, un factor que constituye la otra cara, que no es la constructiva, sino más bien la destructiva, del ser político del hombre. Aristóteles, en la Política, examina con detalle el problema de la ciudad desde los conflictos que la atraviesan constitutivamente. $\mathrm{Y}$ es a partir de estos conflictos (y como veremos, en realidad, a partir de un conflicto muy singular entre ellos) que aparece la exigencia del correctivo de la concordia. Para entender el problema, se tiene que partir, como decíamos al principio, del contenido ambiguo, ambivalente, anfibológico del zôon politikón aristotélico. Por lo tanto, la tendencia a resolver la insuficiencia y entramar organizaciones sociales (anteriores cronológicamente pero posteriores ontológicamente) a la ciudad solo es un aspecto de la existencia política. ¿Cuál es, pues, este otro aspecto?

La otra cara de la política no es ni más ni menos que la lucha de clases: en efecto, no lo que teje y engarza la polis, sino aquello que precisamente la desteje y desgaja. Puede que esta expresión, "lucha de clases", suene temporalmente desfasada con respecto al momento que se está estudiando en este artículo. Con todo, conviene leer atentamente los propios análisis de Aristóteles para darse cuenta de que, en realidad, el término "lucha de clases", de clara apariencia marxista14, no sería más

\footnotetext{
13 Pol., 1253a 10-12.

14 En 1852, Marx escribe a Josep Weydemeyer (1818-1866) que "no me cabe el mérito de haber descubierto la existencia de las clases en la sociedad moderna ni la lucha entre ellas." (Raventós, 2007, p. 65)
} 
que una versión de las relaciones políticas combativas que se observan a partir de muchos otros autores -y entre ellos, de forma eminente, ya en Aristóteles en pleno siglo IV antes de nuestra era. Vayamos, pues, a los textos:

[E]s imposible que los mismos ciudadanos sean a la vez pobres y ricos. Por eso éstos parecen constituir principalmente partes de la ciudad, los ricos y los pobres. Además, por ser, por lo general, unos, pocos, y otros, muchos, estas partes de la ciudad aparecen como contrarias, de modo que según la superioridad de una u otra se establecen los regímenes, y estos parecen ser dos: democracia y oligarquía. ${ }^{15}$

Está claro, pues, que la división de la sociedad que descriptivamente propone el análisis aristotélico se basa en dos grandes "partes" que se definen en función de los recursos materiales (la propiedad o riqueza). Y por si ello fuera poco, a partir de la preponderancia de una de estas dos clases, los pobres y los ricos, aparecen los dos principales regímenes, que Aristóteles llama "democracia" y "oligarquía". Así que las dos partes constitutivas de la polis se corresponden con dos regímenes políticos concretos. Antes de ahondar en esta cuestión, sin embargo, conviene hacer algunas precisiones.

En el libro IV de la Política, Aristóteles analiza todo el conjunto de los distintos regímenes políticos. Es importante resaltar el hecho de que la pluralidad de regímenes políticos implica, incluso antes de analizarlos con detalle, distintas interpretaciones de lo conveniente y lo perjudicial, de lo justo y lo injusto, que como se ha visto serían los motivos del lenguaje (humano) político. "El régimen es una cierta forma de vida de la ciudad." (Pol., 1295b1). En comparación con el resto de animales gregarios, no hay una sola organización colectiva posible. Hay varias (y por eso se habla de "política"). Tampoco, según Aristóteles, en el resto de los animales, hay casa ni ciudad porque ante todo no hay palabra. Toda organización social de la que los mismos hombres se hacen cargo aparece, antes que nada, como un interrogante sobre lo que conviene y sobre lo que es justo: un problema del sentido de la palabra -parecido al problema de la obra propia que correspondería al hombre en general, así como cada artesano hace su propia obra, que Aristóteles plantea en las páginas de la Ética nicomáquea (1027b22). Pero para nada se trata de un debate puramente teórico. Es absolutamente práctico.

El ser político del animal humano es propiamente el ciudadano, y es así como podríamos entender esta obra o "función propia" en el contexto aristotélico (Camps, 2012, p. 41). Pero en la definición del ciudadano, ocurre algo muy peculiar. W. L. Newman muestra lo siguiente:

15 Pol., 1291b 8-13. 
Things which have to do with (or stand in relation to) objects differing in kind and in priority have little or nothing in common, and... constitutions, the object-matter to which the citizen is related, differ in kind and in priority; whence it follows that the citizen under one constitution is different from the citizen under another, and that we must not expect to find various types of citizen possessing much in common. ${ }^{16}$

La ciudadanía, ya en Aristóteles, es una entidad que no se puede definir a partir de un género común al que se pertenezca (ocurre algo muy parecido, por ejemplo, entre otros muchos términos aristotélicos, con la amistad o con el ser ${ }^{17}$ ). Es más, en el libro III de la Política subraya Aristóteles que el ciudadano se dice de muchas maneras, siempre en función de la ciudad concreta que se esté examinando y que además admitiría multitud de "correcciones" o precisiones. En este sentido, concluye: "Un ciudadano sin más, por ningún rasgo se define mejor que por participar en las funciones judiciales y de gobierno." (Pol., 1276a6). Como no hay término común entre las funciones judiciales y las del gobierno, Aristóteles aduce lo siguiente: "Digamos, para distinguirla, magistratura indefinida. Entonces establecemos que los que participan de ella son ciudadanos. Tal es la definición de ciudadano que mejor se adapta a todos los así llamados." (Pol., 1275a8) Esta magistratura indefinida o indeterminada (aóristos arkhé) es la potencialidad de los ciudadanos para ejercer el poder jurídico-político: su reserva de poder en el ámbito de la ciudad. Étienne Balibar ha querido ver la base de la ciudadanía en este poder de instituir o destituir que no se podría limitar ni coartar desde arriba, por decirlo así. ${ }^{18} \mathrm{E} 1$

\footnotetext{
16 Newman, 1887-1902, p. 133.

17 A. W. Price analiza el problema de la definición de estos términos en Love and friendship in Plato and Aristotle.

18 Es interesante la comparación del ciudadano con el esclavo a partir del siguiente pasaje: "Por consiguiente, no hay amistad hacia un esclavo en cuanto esclavo, pero sí en cuanto hombre, porque parece existir una cierta justicia entre todo hombre y todo el que puede participar en una comunidad donde hay ley o convenio, y, por tanto, también amistad en la medida en que cada uno de ellos es un hombre." (E.N., 1161b 5-10, cursivas mías). El esclavo "puede participar" (tiene en común, participa, 1161b5) Compárese con Pol., 1275a20, donde se habla de la participación ciudadana. En el caso de la amistad ética, hay una fundamentación basada en la potencia (dynámenon koinōnêsai); y en la política, en cambio, ya se participa efectivamente. Al parecer, tendríamos la diferencia en el paso de la potencia al acto: el esclavo en tanto que humano podría participar; el ciudadano, en cambio, participaría efectiva y realmente. Pero vemos después que ello es falso por apresurado: el ciudadano no participa en acto tampoco, porque no es el gobernante, que es el que ejerce el poder y actúa -el ciudadano sin más, ejerce, en realidad, una magistratura indeterminada (aóristos arkhế); es el que se reserva un poder frente al poder. El ciudadano es el que participa en acto, por decirlo así, de la potencia de instituir y destituir (en el gobierno y la justicia). Lo que distingue al esclavo (o simplemente, al no ciudadano) del ciudadano no es la potencia del acto. Todos están igualmente en potencia con respecto a la justicia y a la amistad (ético-políticas). Pero el ciudadano tiene un permiso, un acceso y una reserva frente al poder. El esclavo no tiene esta reserva, vive sin reserva. Uno puede participar, el otro podría poder participar (está en una doble potencia con respecto al poder, en una super-potencia). La cesura es el resultado de una convención arbitraria, aunque según Aristóteles existe una justificación
} 
ciudadano cuenta con una posibilidad de resistencia ante el ejercicio del poder por parte del gobernante, por el hecho de que constitutivamente se define por su participación indeterminada. Pero, como dice más adelante Aristóteles, esta caracterización de la ciudadanía es muy próxima a la democracia (1275b10), esto es, a la ciudadanía democrática. Lo cual le da la razón a Balibar en su presentación del quid de la política en Aristóteles como un componente democrático irreductible. (Balibar, 2010)

Ahora bien, debemos pasar de la especulación sobre las posibilidades al cómputo más concreto de las probabilidades. Es decir, el ciudadano puede participar, pero no todos pueden en el mismo grado ni lo hacen en el mismo sentido. Y aquí es donde aparece claramente el factor de clase social al que nos referíamos más arriba. Según algunos historiadores del mundo antiguo, como Geoffrey de Ste Croix, la situación social de la polis griega tendría este aspecto: "Los ciudadanos del estado griego se podrían considerar como una clase especial de terratenientes, frente a los extranjeros, aunque también ellos, a su vez, se pudieran dividir en diferentes clases contrapuestas, de una manera más significativa." (De Ste Croix, 1981, p. 289) Es esta contraposición significativa entre clases la que, de algún modo, representaría la tendencia a la lucha en el campo político.

Esta lucha dio sus frutos. Arthur Rosenberg, otro historiador del mundo clásico, afirma que "en Atenas los no propietarios tuvieron a partir del 461 la mayoría en el Consejo gracias a la norma de igualdad en el sorteo." (Rosenberg, 2006, p. 88). Esto significa que la reforma o revolución de Efialtes (Domènech, 2004, p. 52) constituyó una victoria temporal, esto es, la conquista histórica de la preponderancia política de una de los dos clases en liza. Lo consiguió mediante la ampliación del acceso a los cargos de la asamblea a todos los miembros del cuerpo ciudadano, distribuidos en los distintos demos.

Los demos eran básicamente comunidades de personas que vivían juntas y que, en general, se conocían entre ellas personalmente. Cada una de estas pequeñas circunscripciones debía enviar representantes propios a un organismo destinado a ejercer una influencia determinante sobre el gobierno del estado; en la práctica era una especie de parlamento. 19

\footnotetext{
"natural" de la esclavitud: precisamente la justificación de la amistad con el esclavo en tanto que hombre (y no en tanto que esclavo o "instrumento animado") se basa en su capacidad para desempeñar un papel jurídico en las relaciones amo-esclavo en el seno de lo que Montesquieu, mucho más adelante, llamará la "loi de famille". Por lo tanto, esta cesura o diferenciación entre libre y esclavo es (potencialmente) modificable. La política (en su sentido más fuerte, no el aristotélico), según Rancière y Balibar, sería la lucha por y en esta cesura entre lo natural y lo convencional o arbitrario (entre phýsis y nómos de nuevo). Habría política allí donde se cuestionaría lo instituido como "natural" (esto es, contra lo tradicional y dado por supuesto).

19 Rosenberg, 2006, p. 68.
} 
El hecho de que el sorteo 20 fuera el mecanismo que se impusiera significó un golpe muy duro para los aristócratas: esta "barriocracia" (del demos entendido como barrio) invitaba a cualquiera, en principio, a ejercer la responsabilidad política y judicial si así lo deseaba. En los episodios de reacción oligárquica, todas estas medidas democratizadoras fueron, claro está, rápidamente abolidas y sus partidarios veloz y cruentamente reprimidos.

Lo que diferencia la democracia y la oligarquía entre sí es la pobreza y la riqueza. Y necesariamente cuando ejercen el poder en virtud de la riqueza, ya sean pocos o muchos, es una oligarquía, y cuando lo ejercen los pobres, es una democracia.21

A pesar de que esta cuestión ya se ha hecho notar (Domènech, Raventós), no es inoportuno recordar que en la distinción entre democracia y oligarquía el número de los que gobiernan, ya sean muchos o pocos, la mayoría o la minoría, es accidental con respecto a su condición socioeconómica. Ya Aristóteles en la Ética nicomáquea (1095a 14-26) hablaba de una cierta determinación de los agentes individuales en su actuación política en función de sus recursos económicos. Esto significa, lisa y llanamente, que solo podrán participar activamente en la política aquellos que dispongan del suficiente tiempo libre como para ocuparse de estos temas -y este "tiempo libre" no es más que el resultado lógico de disponer de recursos suficientes para vivir sin depender de nadie o sin tener que ganarse el sustento con el trabajo. Los demás, los pobres, en tanto que jornaleros diseminados por el campo o en tanto que asalariados buscando un trabajo para sobrevivir en la ciudad, tendrán muchas menos oportunidades (probabilidades) de participar políticamente. Dejando de lado la agudeza sociológica no siempre académicamente advertida de esta consideración, lo decisivo aquí es que la definición del campo político se establece desde el conflicto arraigado en las condiciones materiales. Y este conflicto puede desencadenar el peor de los males, esto es, la stásis: la lucha intestina entre las partes de la ciudad que, desgarrándola, acarrea su destrucción. Propietarios y no propietarios, en un combate sin piedad, arruinan la ciudad.

\footnotetext{
20 Jacques Rancière en El odio de la democracia ahonda en esta cuestión del factor del azar en la política. El hecho de que cualquiera pueda ejercer el poder político, a partir de en un sorteo abierto a toda la ciudadanía, ponía los pelos de punta a los defensores de las antiguas legitimaciones del poder, basadas en los honores, la herencia o incluso, como en el caso de las lecciones platónicas, las competencias epistémicas de los aspirantes a reyes filósofos (un antecedente evidente de la tecnocracia que se podría llamar "epistemocracia").

21 Pol., 1279b 39 - 1280a 3.
} 


\section{La propuesta aristotélica de la amistad cívica}

Es desde la perspectiva de la lucha de clases -o de la tendencia pendular entre democracia y oligarquía, con sus consecuencias de frecuente inestabilidad políticaque debe entenderse la preocupación aristotélica por la concordia. Su propuesta política, tradicionalmente, se ha interpretado como un régimen (la politeía, república o timocracia) de las clases medias. No hace falta decir por obvio que estos hoi mésoi de Aristóteles poco o nada tienen que ver con lo que actualmente llamamos "clases medias" -aunque seguramente algunas analogías funcionarían de todos modos. Otro lugar común en la explicación de este paso en Aristóteles es el apresurado símil con la idea del término medio (mesótēs). Es apresurado porque el término medio, en la ética aristotélica, hace referencia a la excelencia o virtud, y este no sería el caso de las clases medias por sí mismas, sino de la aristocracia, en sentido literal (no oligárquico) -o incluso de la figura del monarca, el superior en virtud, de clara inspiración platónica. Con todo, el mismo Aristóteles establece que el régimen de las clases medias, por ser moderado, puede ser también el mejor en un sentido nada trivial: por ser justamente el más estable y permitir la elección de los "mejores" para desempeñar determinados cargos políticos (Pol., 1249b5; E.N., 1167a35). En cualquier caso, lo interesante de la propuesta aristotélica es que sugiere la necesidad de establecer una parte entre las dos partes en lucha, un contingente de ciudadanos que no se puedan volcar ni hacia los propietarios muy ricos ni hacia los no propietarios o propietarios muy pobres. Se trata de una medida casi de "ingeniería socioeconómica" que supuestamente daría unos réditos políticos en términos de estabilidad, a saber, de evitación de la ruptura de la polis. Aquí el cruce entre textos de la política y de la ética ${ }^{22}$ (en esta última, referidos a la concordia o a la comparación entre la amistad y los regímenes políticos) ilustra perfectamente el problema que nos ocupa.

El gobierno de los hermanos se parece a una timocracia, ya que los hermanos son iguales, excepto en cuanto que se diferencian por edad; por esto, si estas diferencias son muy grandes, su amistad ya no es fraternal. 23

En esta analogía con la familia, la cuestión es que la semejanza entre los miembros de la polis, los ciudadanos, al igual que los hermanos en la familia, facilita su unión y cohesión. No deja de tener interés precisamente la idea de una amistad que además puede ser "fraternal" (philía adelphikế). De ahí se deduce la necesidad de algún tipo de igualación, que Aristóteles presume que se puede conseguir a través de la llamada "clase" o "parte media" (hoi mésoi).

22 Que son dos aspectos o partes de un mismo "saber sobre los asuntos humanos". (E.N., 1094a25)

23 E.N., 1161a 3-5. 
Es evidente, por tanto, que la comunidad política mejor es la constituida por la clase media, y que es posible que sean tan bien gobernadas estas ciudades en las que el elemento intermedio es numeroso y más fuerte que los otros dos, o si no, que cada uno de los otros, pues añadiéndose a un elemento produce el equilibrio e impide que se produzcan los excesos contrarios. Por eso es una suerte muy grande que los ciudadanos tengan una fortuna media y suficiente, porque donde unos poseen muchísimo y los otros nada, o surge una democracia extrema o una oligarquía pura o una tiranía 24 debida al exceso de una o de otra. 25

Alianzas políticas entre partes incluidas, la propuesta aristotélica es una "síntesis" (sýnthesis) entre la democracia y la oligarquía (Pol., 1294a9). El Estagirita se inclina por conseguir una mezcla (míxis) entre los elementos de ambos regímenes extremos, que como hemos dicho representan políticamente los intereses de las partes principales de la ciudad y amenazan con cercenarla. En la argumentación aristotélica, es importante aclarar que, precisamente, la política se caracteriza por conseguir un interés común, lo que luego analizaremos como "concordia", alejado de los intereses particulares que no serían propiamente políticos o cívicos 26 . El paradigma que Aristóteles emplea para ilustrar su operación de combinación (sociológica) entre las partes de la ciudad y combinación (política) entre los regímenes es el de la mezcla (se trata de engendrar la política ${ }^{27}$, a partir de las partes o porciones

\footnotetext{
${ }^{24}$ Es interesante comparar este pasaje de Aristóteles con respecto a la tiranía con este otro: "La tiranía es una monarquía que atiende al interés del monarca, la oligarquía al interés de los ricos, y la democracia el interés de los pobres" (Pol., 1279b5). ¿Cuál es el interés del monarca o tirano en este paso? Pues bien, a partir de la idea de que la tiranía surge a partir del exceso de uno u otra (democracia u oligarquía), se ve claro que esta forma de gobierno monárquica, en la que manda uno solo y no lo hace en interés de la ciudad, en realidad se apoya siempre en una de los partes de la ciudad. La tiranía, como tal, es espuria en el cómputo sociológico-político entre clases y regímenes, ya que siempre se acaba reduciendo a uno u otro en términos prácticos. La monarquía o la aristocracia serían las formas superiores de conseguir lo que la república trata de establecer: la definición de "lo común" por encima de las diferencias de clase.

25 Pol., 1295b10-1296a1.

26 "Sin embargo, la mayoría de los hombres políticos no merecen verdaderamente ser llamados así, pues no son, en verdad, políticos, ya que político es el hombre que elige las bellas acciones por ellas mismas, mientras que la mayor parte de los hombres abrazan esta vida por dinero y provecho." (E.E., 1216a 20-25). Aquí la cuestión es que la vida política que no se desempeña virtuosamente deja de ser "política", no solo en el sentido del buen uso del poder político (o de la buena administración del estado), sino también en el sentido cívico más elemental. ¿Cuál es la intuición que resuena en este pasaje? Pues evidentemente que el campo ciudadano posibilita un tipo de acciones, entendidas desde la praxis, que superan el comportamiento por mero interés, es decir, la acción instrumental meramente productiva o técnica. El ámbito de la ciudad crea un espacio abierto que permite tipos de relaciones que van más allá de la necesidad o el interés y que, en consecuencia, son más plenas y ricas (virtuosas o excelentes en la medida en que, en calidad de autotélicas, valen por sí mismas).

27 ' [I]t emerges that the political legislator's task in Aristotle's view is more properly conceived on a reproductive rather than on a productive model: the primary aim of the legislator praxis is to cultivate
} 
que constitutivamente la componen, por mixtura). El objetivo es conseguir una proporción que obviamente siempre estará determinada por los caracteres materiales y reales de cada contexto particular (Pol., 1296b12), con lo cual es una mezcla sin fórmulas genéricas, universales y necesarias; es decir, es una química basada en la prudencia o adecuación de las fórmulas a las situaciones (una química sin laboratorio, es decir, se parecería más al modelo de la cocina que al de la alquimia). Pero es siempre combinación al fin y al cabo: los términos "síntesis" y "mezcla" así lo acreditan. Y esta combinación da con una forma de vida, un alma, de la ciudad: el paralelismo con la dinámica del carácter ético es casi inevitable. Se saludan la moderación y la estabilidad como las conquistas del régimen ciudadano por antonomasia (politeía) y además se entrelazan las vidas de los ciudadanos con su trato cotidiano 28 . Por encima de todo, el régimen de tipo medio, dice Aristóteles, es el mejor porque está libre de sediciones y discordias entre los ciudadanos (Pol., 1296a12).

La amistad de los hermanos se parece a la de los compañeros, porque son iguales y de la misma edad, y tales personas son muy semejantes en sentimientos y en caracteres. También se parece a ésta la amistad de los miembros en una timocracia, pues en ella los ciudadanos aspiran a ser iguales y equitativos, $\mathrm{y}$, por tanto, gobiernan por turnos y por igual: por consiguiente, la amistad también es así. ${ }^{29}$

Este tipo de amistad cívica se concretará más adelante (E.N., IX, 6) en la forma de la concordia (homónoia). Ante la amenaza del desgarro de la ciudad, Aristóteles ensaya una estrategia de cohesión entre "ambas partes" (E.N., 1167a30) en lucha o entre todos los miembros de la polis. Aubenque afirma en este sentido:

friendship, unanimity, and equality between citizens rather than seeking to produce, say, more goods or mere coordinated behaviour (...) The differences between personal reproductive activity and the legislator's public or civic one can now also come to light; the differences will follow roughly the same lines as those distinguishing personal from political friendship. That is, in the case of personal reproductive activity, close emotional ties are furthered and maintained, one does particular things for the friend in the concrete, whereas in the case of civic reproduction such reciprocal "liking" and "doing" works via the political process, the constitution, and the public standards of acceptable civic behaviour. Hence, I may personally dislike a fellow citizen of mine and yet remain his civic friend." (Schwarzenbach, 1998, pp. 107-108) Contra la tesis de Arendt, el legislador no sería tanto un "productor" como un "reproductor" (una de las connotaciones del término "míxis" así lo podría sugerir).

28 "Insofar as the city-state is for Aristotle, and for other Greeks of the classical period, a community of free and equal citizens who share in ruling and being ruled in turn, the social virtues of Aristotle adumbrates are crucial for generating and maintaining the reciprocal relationship necessary to political life -necessary, in other words, to prevent the political relationship between citizens from devolving into one of mastery and servitude. Aristotle's conception of wittiness as a virtue indicates an appreciation of how both "everyday talk" between citizens shapes the ways in which they act toward and deliberate with each other, but also how their everyday laughter and joking function in this way." (Lombardini, 2013, p. 212)

${ }^{29}$ E.N., 1161a 25-30. 
Dans le beau passage qui montre que le sage lui-même, même s'il n'en a pas à proprement parler besoin, redouble et intensifie par la conscience qu'il a de l'existence des amis le plaisir qu'il ressent à la sienne propre, Aristote montre que, pour les hommes,

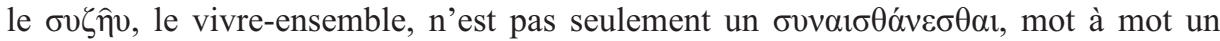

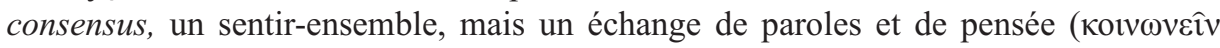

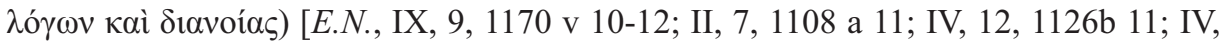
$14,118 \mathrm{~b} 5]$. C'est là qui différencie les hommes des bestiaux, dont le vivre-ensemble consiste à paître ensemble dans le même pré. Koinonein ne peut avoir ici le sens passif de participation à un ordre existant, mais nomme la communication active et réciproque qui permet de constituer cet ordre. ${ }^{30}$

La concordia sería una estilización de esta tendencia comunitaria que señala Aubenque, la cual sobrepasa el mero consenso en sentido literal, esto es, el tener las mismas sensaciones. La unanimidad de la concordia, no obstante, dista también de ser puramente teórica. "Tampoco se dice que los que tienen los mismos pensamientos sobre cualquier cosa son amigos, por ejemplo, los que piensan lo mismo sobre los fenómenos celestes (porque ser del mismo parecer sobre estas cosas no supone amistad)" (E.N., 1167a25). Se trata de acordar una unanimidad con respecto a los objetos de deliberación, no de ciencia (como se sabe, no se delibera ni sobre lo necesario (E.N., 1112a20), ni sobre cuestiones de hecho (E.N., 1113a3) ni sobre lo imposible). Tampoco se delibera sobre los fines, sino solo sobre los medios (E.N., 1112b10) para alcanzar tales fines -aunque evidentemente no se trata aquí de reducir la deliberación a cuestiones puramente técnicas o instrumentales. El objetivo es construir una prudencia que vaya más allá de la figura individual o modelo del ciudadano prudente. Se trata, en una palabra, de pasar del ciudadano prudente (paradigma en la ética para la definición de la virtud) a la ciudadanía prudente (paradigma para el régimen por antonomasia, la polietía). Y este paso solo es posible mediante la concordia, como tipo de amistad cívica y, por tanto, como derivado de la amistad. 'C'est la raison pour laquelle, dans une cité où règne la concorde (homónoia), qui est une sorte d'amitié civique, la justice ne disparaît pas, mais a moins besoin de se manifester sous la forme des lois écrites. L'unanimisme rend le juridisme inutile." (Aubenque, 2009, p. 118)

Por tanto, los hombres son del mismo parecer en lo práctico, y dentro de esto, en aquellas materias que son de considerable importancia y pueden pertenecer a ambas partes o a todos, y éste en el caso de las ciudades, cuando todos los ciudadanos opinan que las magistraturas deben ser elegibles, o que se debe hacer una alianza guerrera con los lacedemonios, o que Pítaco debe gobernar cuando él también lo quiere. Pero cuando cada uno quiere ser el que mande, como los capitanes en Las fenicias, surge la discordia: porque la unanimidad no radica en pensar todos lo mismo, sea lo que fuere, sino en pensar

30 Aubenque, 2009, p. 119. 
lo mismo sobre la misma cosa, como cuando el pueblo y las clases selectas piensan que deben gobernar los mejores; pues de esta manera todos obtienen lo que desean. Así pues, la concordia parece ser una amistad civil, como se dice, pues está relacionada con lo que conviene y con lo que afecta a nuestra vida. ${ }^{31}$

La estrategia aristotélica se revela, así, perfectamente: como es harto sabido, la amistad cívica sirve para contrarrestar la tendencia opuesta a la unidad de la polis: la lucha intestina 32 . Para ello, parece que en la lucha entre las partes de la ciudad los extremos democráticos y oligárquicos se han de evitar como sea ${ }^{33}$. Es más, en este tipo de régimen suceden dos fenómenos dignos de mención: en primer lugar, Aristóteles explica que en la república (o timocracia o politeía) algunos percibirán, según su punto de vista, que se trata de una democracia y otros, en cambio, de una oligarquía. Este aspecto demuestra que la cuestión del régimen ciudadano (o político) por antonomasia tiene un carácter marcadamente contextual-prudencial. Esta es una de las ventajas más importantes de la constitución mixta ${ }^{34}$. Pero es que, en segundo lugar, añade Aristóteles, la república de las clases medias (que ni "rehúyen los cargos y menos los ambicionan" [Pol., 1295b, 10-15]) es lo que permite una verdadera koinōnía politikè (comunidad política o sociedad civil), en la medida en que no se habrá establecido un poder desgajado de una parte de la ciudadanía contra la otra, ya sea en la democracia extrema o en la oligarquía pura. Habrá correspondencia entre el poder público y los ciudadanos. 35 Por último, la idea de concordia con-

31 E.N., 1167a20-1167b.

$32 \mathrm{La}$ tesis de la función de la amistad como antídoto contra la lucha intestina en la ciudad era un lugar común desde la sofística o incluso la filosofía presocrática, lugar común que Aristóteles también señala (véase, entre otros, Kalimtzis, Konstan, Ludwig y Schwarzenbach).

33 Si ello no es posible, Aristóteles prefiere la estabilidad del régimen a los cambios subversivos. Es lo que C. Horn llama "political loyalism": "The decisive consequence for political loyalism is this: any political change (kinêsis or metabolê) would radically alter, according to Aristotle, the conditions of agency for the citizens. Hence it is better to improve democracies qua democracies and oligarchies qua oligarchies than to radically transform a given constitution. Since people are brought up with the old laws and since their characters are deeply shaped by them, it is a great danger to revise established social rules. Aristotle's account of moral education has, to some extent at least, a 'behaviorist' flavor: citizens who are raised up under a certain constitution do reflect exactly the laws and rules they followed so far. Aristotle claims that the constitution is, as it were, the way of life (bios) of a city (IV 11, 1295a40-b1).”(Horn, 2013, p. 235)

34 El concepto de "constitución mixta" es de gran importancia en el pensamiento político antiguo y ha dado lugar a una abundante bibliografía. Para un análisis sobre este concepto en el marco de la filosofía política de la Grecia antigua, véase: "The Mixed Constitution in Greek Thought" (Hahm, 2009). 35 El caso extremo de desunión entre el poder político y los ciudadanos lo representa la tiranía (como una forma de destrucción del espacio político). En este caso, según Platón y Aristóteles, el poder se vuelve despótico al eliminar propiamente las relaciones políticas entre gobernantes y gobernados -es algo parecido a una esclavización de la ciudadanía. Y, no menos importante, se gobierna siempre (o casi siempre) desde el interés propio de la facción social que apoya al tirano. Es sugerente comparar esta idea común de la tiranía con una reflexión muy posterior de Arthur Rosenberg sobre el mundo antiguo: "El papel desempeñado desde la cumbre del poder por hombres como Pisístrato, en los esta- 
lleva un potencial de cooperación que Aristóteles resalta en sus análisis de la amistad cívica: para obtener tal unanimidad, las psicologías de los ciudadanos deben ser virtuosas (deben estar en concordancia consigo mismos y entre sí), puesto que en caso contrario desearán más de lo que aportarán, con lo cual reaparecerá el problema de potenciales free riders y de las peleas en la ciudad (Domènech, 2004, p. 46). Esta cooperación conllevará una abundancia de bienes públicos. En definitiva, la propuesta política aristotélica, en el plano teórico, se presenta como una mezcla que tiende a la imparcialidad políticas para conseguir la cohesión ciudadana y evitar los enfrentamientos o insurrecciones. Esta es su pretensión más clara y patente. Se consigue la concordia cuando todas las partes obtienen lo que quieren (E.N., 1167a35).

\section{Recontextualización: la democracia plebeya ante la propuesta aristotélica}

Aristóteles no crea desde el vacío sus análisis políticos y sus propuestas correctivas, estilizadas, sobre la república o timocracia. Sin una atención al contexto histórico, a los regímenes realmente existentes en la época estudiada, parece que Aristóteles simplemente se mueva en una consideración teórica neutra que busque el término medio entre toda la variopinta oferta de regímenes políticos posibles. No es así, sin embargo. Aristóteles, en realidad, está presentando un second best en materia política. Su opción política favorita es la aristocracia o aún la monarquía virtuosa. Lo que sucede es que no encuentra ejemplos o casos reales y presentes que avalen su factibilidad. Es entonces cuando, a partir del régimen establecido de la democracia plebeya ateniense, desarrolla su teoría política republicana. Es una respuesta a una configuración sociopolítica realmente existente y no una abstracción desarraigada de las condiciones materiales concretas.

dos griegos del siglo VI antes de nuestra era, fue denominado "tiranía" y ellos mismos fueron llamados "tiranos". Esta palabra ha tenido una historia singular, porque en la actualidad designa a un hombre que domina mediante la brutalidad y la violencia. Para los griegos, por el contrario, la palabra týrannos en su origen significaba algo así como "príncipe" o "rey". A continuación fue utilizada para designar a un hombre que, en un estado dotado de instituciones formalmente republicanas, ejercía de hecho un poder absoluto. Estos antiguos tiranos no eran de ningún modo déspotas brutales y opresores del pueblo, sino, por el contrario, hombres que gozaban de la confianza de las masas y representaban los intereses de la burguesía en sus controversias con la nobleza. Sólo con el transcurso del tiempo, cuando la institución de la tiranía resultó inadecuada y también en conflicto con la voluntad popular, la palabra adquirió este sentido (ese mal gustillo) peyorativo que aún conserva." (Rosenberg, 2006, pp. 64-65). Siglos más tarde de la época clásica, el esquema continuará intacto en el Mediterráneo renacentista: "El principado es creado o por el pueblo o por los grandes, según que una u otra de estas partes encuentre la ocasión. Porque, cuando los grandes ven que es imposible resistir al pueblo, empiezan a acrecentar la reputación de uno de ellos y lo convierten en príncipe para poder así, bajo su sombra, acrecentar sus apetitos. El pueblo, a su vez, viendo que no puede resistirse a los grandes, acrecienta la reputación de alguien y lo convierte en príncipe para defenderse con su autoridad." (Maquiavelo, 1997, p. 106) 
Nosotros y los nuestros, todos hermanos de una sola madre, no creemos que seamos esclavos los unos de los otros, sino que la igualdad de nacimiento según naturaleza nos fuerza a buscar una igualdad política según ley, y a no ceder entre nosotros ante ninguna otra cosa sino ante la opinión de la virtud y de la sensatez. ${ }^{36}$

Estas palabras de Aspasia, una dirigente, mujer, precisamente, del partido democrático de Atenas resuenan en uno de los diálogos de Platón. La democracia extrema tenía sus defensores y militantes. Uno de los inconvenientes más graves a la hora de buscar referencias directas sobre la reivindicación del régimen democrático es que lo que se ha conservado es, en su mayoría, crítica filosófica hostil a la democracia (Platón y, en menor grado, pero también hostil al fin y al cabo, Aristóteles). Tenemos, ciertamente, la Oración Fúnebre atribuida a Pericles por Tucídides, donde se halla uno de los elogios más sentidos de la democracia ateniense (con tintes imperialistas, todo sea dicho). Tenemos, además, La vida de Pericles de Plutarco. $\mathrm{O}$ algunos ramilletes de declaraciones políticas democráticas en autores que se disponen a objetar, desmontar o rechazar de plano estas mismas posiciones. Pero entre todos los posibles rastros de este régimen tenemos el Protágoras de Platón, cuyo tema, como se sabe, versa sobre si la virtud política puede enseñarse.

Dado que Protágoras fue un aliado de Pericles y Aspasia (Rodrígez Adrados, 1975), es muy relevante conocer la posición de Platón -declarado enemigo de la democracia ateniense- al respecto. En este diálogo, aparece el conocido mito de Prometeo y Epimeteo. Como se sabe, allí Protágoras defiende que el sentido de la justicia (dikkē) y del pudor o vergüenza (aidós) son algo universal y equitativamente distribuido entre el género humano. Como estos dos elementos constituyen la base de la politikè areté (virtud política) y de la politikè tékhnē (arte político), la capacidad de participación política (y de participación virtuosa) no estará destinada a unos pocos elegidos, ya sean los más ricos o los teóricamente más competentes (Domènech, 2004, p. 56). Esta capacidad es, pues, universal. ${ }^{37}$ Esta línea de argumentación choca, por decirlo así, contra los planes de la Academia platónica de formación de cuadros dirigentes, con lo cual la tarea de la política se convertiría en ciencia: es decir, en conocimiento de un tipo superior a estas capacidades universales, defendidas por Protágoras, que por experiencia se pueden ir moldeando y agudizando en todos los hombres.

\footnotetext{
36 Platón, Menéxeno, 239a.

37 "Pues estos fueron distribuidas así. Con un solo hombre que posea el arte de la medicina, basta para tratar a muchos, legos en la materia; y lo mismo ocurre con las demás profesiones. ¿Reparto así la justicia y el poder entre los hombres, o bien las distribuyo entre todos? "Entre todos" respondió Zeus; "y que todos participen de ellas; porque si participan de ellas solo unos pocos, como ocurre con las demás artes, jamás habrá ciudades. Además, establecerás en mi nombre esta ley: Que todo aquel que sea incapaz de participar del pudor y de la justicia sea eliminado, como una peste, de la ciudad." (Protágoras, 321d)
} 
Esta es la respuesta platónica al elogio de Aspasia a la sensatez o a la defensa de Protágoras de un sentido de la justicia por parte de todos los ciudadanos: los demócratas no tendrían en cuenta que los necios no pueden gobernar. Sin duda, es una de las formas que toma el choque entre sofística y filosofía (que por otro lado en Las nubes Aristófanes se demuestra que no estaba unánimemente asumido), es decir, entre dóxa y epistếmē. Si la política se ocupa de lo particular, el conocimiento general -basado en el modelo de la dialéctica platónica o incluso de la matemática pitagórica- de poco servirá. Será más una cuestión de dóxa: de opiniones sobre lo verosímil, lo razonable, lo probable (materia y objeto de estudio de la retórica). Y esta es la batalla de Platón: desacreditar la retórica como medio de acción política (de forma muy explícita en el Gorgias) para fundar un conocimiento en sentido fuerte que pueda llegar a ocuparse de la política.

Otra línea de acción es la de la fraternidad o amistad cívica, como se puede leer claramente en el fragmento que reproduce las palabras de Aspasia. Aristóteles, que en un pasaje de la Ética nicomáquea había identificado la democracia con la anarquía, es decir, con la ausencia de gobierno (1161a5), admite un poco más adelante algo crucial: "Por eso, también en las tiranías hay amistades y justicia, pero en pequeña medida, y en medida mayor en las democracias, donde los ciudadanos, siendo iguales, tienen muchas cosas en común." (E.N., 1161b10) Resuena en este pasaje el dicho pitagórico, que repetirán tanto Platón como Aristóteles: "las cosas de los amigos son comunes". Pero universalizado en la comunidad política, lo cual implica un cambio fundamental con respecto a la cita original. Aquí casi se podría decir que la democracia se asocia a una especie de comunismo, de movimiento de igualación y emancipación. En cualquier caso, lo importante es que la idea de amistad y fraternidad civil nace con la democracia, como también lo es la perspectiva de lo particular en los asuntos políticos, es decir, el uso del sentido común, la sensatez o el sentido de la justicia que, en principio, estarían al alcance de cualquiera con suficiente experiencia. Y es entre los extremos de la democracia real plebeya ateniense postefiáltica (hay una discusión abierta entre la validez de las políticas de los dos grandes líderes populares postefiálticos, Pericles y Cleón ${ }^{38}$ ) y la crítica ideal (epistémica) platónica, donde se sitúa el punto de arranque de la Política de Aristóteles. La mezcla está entre una forma de gobierno y una estructura social determinada (marcada por la preponderancia de las clases populares) y la atracción de una crítica filosófica de pretensiones científicas (o epistémicas) basada en el tándem Sócrates-Platón. Aristóteles estaría, entonces, realizando nuevamente una mezcla o síntesis entre dos polos opuestos. Estaría aplicando, prudencialmente, las intuiciones maestras de la crítica epistémica de raigambre aristocrática (u oligárquica) al diseño institucional de la democracia popular.

38 "Cleón era de la opinión de que los dirigentes del partido de Pericles estaban perjudicando de forma irremediable la causa. Y de ahí su intento de alejar a las masas de aquellos dirigentes ineptos." (Rosenberg, 2006, p. 109) 
Desde esta óptica, ahora pasaremos a analizar estos dos componentes: la prudencia y la concordia. Comencemos con el primero. La prudencia en Aristóteles es precisamente una de las versiones correctivas más importantes que introduce. Platón (Protágoras, 330b) la había definido como virtud de la sensatez, de la parte racional y superior del alma. Si con la concordia ciudadana, basada en la república como régimen correctivo con respecto a la democracia, Aristóteles estaba rebajando la fuerza hegemónica democrática, con la idea de prudencia está realizando una fuerte crítica a Platón. No hay ciencia de lo particular. Así, el conocimiento, por sí solo, siempre será insuficiente en el campo de la política o de la ética (esto es, en el campo del saber sobre los asuntos humanos, las hoy llamadas "ciencias sociales") ${ }^{39}$. Hará falta un suplemento de saber práctico, de una virtud dianoética (intelectual) distinta de la sophía. Esto es la phrónēsis: un saber relativo a las circunstancias. Un cuidado especial a lo que hoy llamaríamos el "contexto" de la acción (el momento, el lugar, el modo, la compañía, etc.). La incorporación de esta virtud intelectual en el cómputo de las virtudes aristotélicas tiene una gran importancia estratégica: es una forma de adoptar, en un punto crucial, una de las posiciones clásicas de la sofística. Como es sabido, la dicotomía entre dogmatismo y relativismo es un lugar común del debate entre Platón y los sofistas. Aristóteles no se adhiere, ni mucho menos, a la posición sofista. Con todo, reserva una de las intuiciones sofistas más importantes precisamente en el campo de la deliberación a partir de la idea de las acciones prudenciales, que deben acomodarse oportunamente a las circunstancias que rodean cada situación (E.N., 1106b 23-25). La retórica (y con ella, la sofística), desde sus inicios, había renunciado a la búsqueda de la verdad y se había limitado a la verosimilitud. Esta renuncia no acarreaba, salvo en el supuesto nihilismo epistemológico de Gorgias, un rechazo a abordar la realidad. Lo que sucedía, más bien, es que se utilizaban los mecanismos de la opinión, variable, contingente, aproximativa, para acercarse a las soluciones más adecuadas. En este sentido, la práctica retórica de los dobles argumentos, por ejemplo, funcionaba para perfeccionar, técnicamente, esta capacidad de analizar las situaciones desde lo que hoy denominaríamos "todas las perspectivas". La prudencia, en Aristóteles, implica una atención especial a las particularidades y no funciona nunca desde la exactitud, sino desde la aproximación y, por lo tanto, también tiene en cuenta una cierta relativización de los preceptos 40 . A partir de estas características de la prudencia, se podría establecer un

\footnotetext{
39 "Ser virtuoso o ser buena persona no es una actividad estrictamente racional, teorética, derivada -como quería Platón- de la visión de lo que es bueno, pues para que la apreciación de lo bueno mueva a la persona a actuar en consecuencia es preciso inculcarle un estado de ánimo que le haga estimar el bien. No basta con un discurso teórico perfecto que nos diga qué debemos hacer o cómo debemos ser. Hace falta que ese discurso sea elocuente y vaya acompañado de retórica para que se inscriba en el interior del alma humana y la disponga a hacer el bien." (Camps, 2012, p. 56)

40 El valiosísimo libro de Pierre Aubenque La prudence chez Aristote ilumina muchos aspectos de esta virtud central en la ética aristotélica.
} 
acercamiento de Aristóteles a las tesis de la sofística así como un alejamiento a las de Platón. Y es que la prudencia tiene un papel decisivo en la argumentación y el uso de la retórica en el campo de los asuntos humanos, es decir, en la ética y la política. La retórica implica una atención a los demás (Ret. I.2.11) y por lo tanto un reconocimiento a la diversidad de posiciones o, al menos, a la necesidad de persuadir (una supuesta verdad, por sí misma, siempre será insuficiente). Como apunta Susan Bickford (1996, p. 416), "Aristotle tells us that both rhetoric and deliberation are concerned with matters that can be other than they are (Ret. I.2.12-14; EN, 1140a10)." La contingencia constituye el campo de la deliberación retórica, de todo punto política, y poco o nada tiene que ver con el conocimiento en sentido platónicamente estricto (aunque por otra parte también es cierto que la retórica no agota todo el ámbito de la deliberación).

Y en segundo lugar, está la cuestión de la concordia. Como hemos dicho, Aristóteles añade una tendencia oligárquica que atenúe los efectos socializantes y redistributivos de la democracia plebeya. Y desde su particular apreciación aparece el reclamo de la cohesión civil como término medio entre la democracia y la oligarquía, del mismo modo que el término medio en ética es imposible sin la prudencia que lo guíe. Aunque sea como una respuesta a una versión de la fraternidad que estaba llevando al límite todo el montaje de la polis, en Aristóteles tenemos una primera teorización explícita de lo que luego, con el paso de los siglos, se dará en llamar "fraternidad". Esta versión extrema de la fraternidad que Aristóteles podría estar rebajando con su propuesta teórica, nos la da, por ejemplo, el siguiente fragmento de Antifonte:

Todos somos por naturaleza y nacimiento idénticos, griegos o bárbaros. Ninguno de nosotros ha sido distinguido por su origen como bárbaro o como griego y todos respiramos aire por la boca y por la nariz. 41

Constituye toda una revolución con respecto a los presupuestos de la política helénica. La diferenciación entre griegos y bárbaros se hacía cada vez más insostenible. Pero todavía hay más: Platón había hablado de la democracia plebeya como del gobierno de la masa (aquella bestia de múltiples cabezas manipulada por la retórica que se dibuja en la República). Y Aristóteles había llegado a decir que, con la democracia, el ámbito de la vida privada llega a tal libertinaje que los esclavos se liberan (doúlōn ánesis) y gobiernan las mujeres (gynaikokratía). Lo cierto es que en la democracia ateniense mujeres y esclavos podían asistir a las asambleas, pero no tenían derecho a voto. Difuminar las diferencias entre pobres y ricos, extranjeros y ciudadanos, bárbaros y griegos, amos y esclavos y, por último, mujeres y hombres

41 Antifonte, frag. 44a, B, col. 2. 
representaba la liquidación de la polis estable que Aristóteles 42 , en un mundo crepuscular, todavía quería mantener a toda costa. Este movimiento de amistad por igualación y emancipación, típicamente democrático, es lo que a lo largo de la historia se ha dado en llamar "fraternidad". Aristóteles mezcla este componente explosivo, revolucionario, de amistad cívica con el sistema republicano, moderado, de las clases medias. Su resultado es la concordia (que tendrá su réplica en la concordia ordinorum de Cicerón y su antecedente en la harmonía entre estamentos representada en la República platónica): a saber, una forma de mantener unida la ciudad sin que sea víctima de sus luchas intestinas pero también para evitar cambios sustanciales (revolucionarios) en ella. Escribe Balibar:

Ese parece el precio que se debe pagar para la instauración del consenso, del equilibrio o de la homónoia, de la estabilidad política. O mejor dicho, es el precio exigido por la instauración del consenso en lugar del conflicto (la lucha de clases en sentido general, pero asimismo la lucha entre "mayorías" y "minorías" de toda naturaleza), y entonces por la supresión de estos conflictos fuera del espacio público. 43

\footnotetext{
42 La lógica aristotélica parece apuntar siempre a la emergencia de cualidades que son irreductibles a los elementos anteriores. Pero nunca da cuenta de ello totalmente. Por ejemplo: la amistad virtuosa no nace del mero placer o de la utilidad, pero la virtud las subsume. Tampoco la ciudad surge de las casas y las aldeas. Pero esta también las subsume en un bien mayor. Cuando esto sucede, los elementos sueltos (separados) empiezan a funcionar para un fin ulterior, es decir, a salir de sí mismos. Hay algo que parece que va a recibir las funciones, a reorganizar y establecerse teleológicamente como una nueva totalidad. Sin esto, las partes todavía son posibles: pero como elementos separados, piezas sueltas (Política 1253a10). Pero ello, sea lo que sea, lo completa, lo fija (y lo subordina). El misterio es: ¿cómo se genera? Aristóteles habla de una tendencia en el caso de la ciudad y de la virtud. La ciudad subsiste para el vivir bien: introduce una cualidad, la lógica de lo cualitativo (virtud). Se trata de ver algo que en el fondo es un interrogante (¿Qué es vivir bien? ¿Cuál es la obra propia del hombre?). La fuerza natural (tendencia) es una exigencia en forma de tarea. Más allá de la conservación: hay algo que se hace, que se pone en obra. La política en Aristóteles (y junto a ella la ética) tiende a ser el factor que perfecciona, completa, cualifica, subsume y encaja las partes (no mecánicamente, sino como organización del movimiento desde un paradigma biológico). Pero en realidad es todo lo contrario: la política implica su dislocación, aquello que impide que las cuentas cuadren y se cierre el círculo. Es movimiento nunca organizado completamente (pero tampoco puro desorden). La política no es el cierre (la pólis en Aristóteles es el cierre, tanto es así que el expansionismo de Alejandro es visto como una regresión por el hecho de destruir la forma pólis, de exceder el círculo político a través de la acción imperial, como en un sentido totalmente opuesto también lo era la democratización radical de la ciudad). La política es la apertura (una apuesta doble: lo peor y lo mejor del hombre): y el lugar por donde se abre la política es la exigencia de comunidad, inventada y reinventada por lo común. Lo común es tarea. Tarea porque es esfuerzo para poder desplegar aquello que se posee pasivamente (hay una participación pasiva y una participación activa). Político (politikón) porque con-vive. Convivir es esfuerzo, la política es esfuerzo, la educación cívica es esfuerzo, es acción sustantivada. Pero el secreto de la política, precisamente, está en el intento nunca alcanzado de definir lo común, que es aquello que se comparte (koinōneîn).

43 Balibar, 2013, p. 32.
} 
Lo que nos ha sido legado con la formidable teoría aristotélica es el rastro de un reto político urgente y gigantesco pero que a la vez se hunde en la oscuridad de los tiempos. Pensar las formas de la amistad cívica es un profundo desafío para la filosofía política.

\section{Repensar la fraternidad: una tarea para la filosofía política contemporánea}

Es conocida la frase de Robert Nozick en la que afirmaba que hoy en día los que hacen filosofía política deben trabajar según la teoría de Rawls o bien explicar por qué no lo hacen. Huelga decir que Una teoría de la justicia es una obra capital del pensamiento político contemporáneo. Aquí, al contrario de la constatación aristotélica sobre la amistad, podríamos decir que los legisladores y los teóricos políticos se afanan más por la justicia que por cualquier otra cosa. La centralidad de la justicia -y de las relaciones entre la libertad y la igualdad-en la filosofía política ha sido indudable durante decenios. No obstante, la cuestión de la amistad cívica o la fraternidad tenía un peso enorme en los inicios del pensamiento político. No ha sido así posteriormente. En parte, porque la cuestión de la libertad individual, desde la perspectiva moderna, era totalmente desconocida en los tiempos de Aristóteles. John Rawls hace el siguiente diagnóstico:

In comparison with liberty and equality, the idea of fraternity has had a lesser place in democratic theory. It is thought to be less specifically a political concept, not in itself defining any of the democratic rights but conveying instead certain attitudes of mind and forms of conduct without which we would lose sight of the values expressed by these rights. 44

Rawls, no obstante, va un poco más lejos. Si bien concluye que la fraternidad es un concepto menos específico, reconoce textualmente que puede inspirar la concreción de los valores y principios democráticos. De hecho, arguye que el principio de la diferencia traduce el ideal de fraternidad en su interpretación de los principios de justicia en función de la triada revolucionaria francesa:

On this interpretation, then, the principle of fraternity is a perfectly feasible standard. Once we accept it we can associate the traditional ideas of liberty, equality, and fraternity with the democratic interpretation of the two principles of justice as follows: liberty corresponds to the first principle, equality to the idea of equality in the first principle together with equality of fair opportunity, and fraternity to the difference principle. In this way we have found a place for the conception of fraternity in the democratic interpretation of the two principles, and we see that it imposes a definite requirement on the

${ }_{44}$ Rawls, 1999, p. 90. 
basic structure of society. The other aspects of fraternity should not be forgotten, but the difference principle expresses its fundamental meaning from the standpoint of social justice. 45

Que la redistribución de la riqueza en términos de justicia social, como segunda parte del segundo principio de la justicia rawlsiano, corresponda a la fraternidad es, de hecho, perfectamente congruente con la tradición de la idea de la necesidad de una cierta amistad cívica que cohesione la sociedad, es decir, que impida unas desigualdades tan grandes que acaben fragmentando una sociedad bien ordenada. Esta es una posible base para repensar la fraternidad en la filosofía política contemporánea, lo cual, salvando todas las distancias posibles, refleja todavía la intuición aristotélica sobre la concordia civil.

Repensar la fraternidad en la filosofía política contemporánea es una tarea que puede seguir dos caminos bien distintos, que de hecho ya fueron trazados en sus inicios históricos en los albores del pensamiento político: o bien la vertiente de una mayor cohesión en la sociedad para evitar su desgarro, en la que el solidarismo 46 del siglo XIX francés de autores como Marion, Buisson o Bourgeois sería un caso paradigmático o bien la idea de emancipación de todos los estratos subalternos de la sociedad para transformarla radicalmente, en la que Marx o la idea revolucionaria francesa de fraternidad, de raigambre jacobina, sería el otro caso paradigmático. Como vemos, esto no es más que una continuación, a siglos de distancia, de los debates originarios sobre la fraternidad. La cuestión abierta ahora no es solo cuál podría ser el lugar y la concreción de la fraternidad en una teoría de la justicia de corte rawlsiano, sino también qué nuevas mezclas y síntesis -o qué nuevos posicionamientos- entre estas dos tendencias históricas son posibles en la actualidad. Como afirma Schwarzenbach (1996, p. 98), "philia must again be acknowledged as an essential factor unifying even the just modern state." Esta prolongada desatención del potencial político de la amistad ya ha comenzado a revertir.

\section{Referencias bibliográficas}

Arendt, H. 1958. The Human Condition. Chicago: University of Chicago Press. ARISTÓTELES. 1985. Ética nicomáquea. Ética eudemia. Madrid: Gredos.

45 Rawls, 1999, p. 91.

46 "On attend d'une nouvelle "science sociale" la réponse aux questions fondamentales suscités par les divisions entre clases. Quels sont les véritables liens qui unissent les hommes? Peut-on formuler la loi de leurs rapports mutuels? Il s'agit, en effet, de démontrer qu'au-delà des conflits apparents l'humanité est promise à l'unité. Tous les milieux, qu'ils soient traditionalistes ou progressistes, sont en fait traversés par le même souci: comment retrouver l'unité perdue? (...) Le noyau germinal de l'idée de solidarité: au-delà des conflits apparents, il faut chercher, derrière le visible, les liens invisibles, ontologiques, qui relient tous les hommes." (Blais, 2007, pp. 60-62) 
Aristóteles. 1988. Política. Madrid: Gredos.

Aristóteles. 1990. Retórica. Madrid. Gredos.

Antifonte. 2002 Antiphon the Sophist. The Fragments. Cambridge : Cambridge University Press.

Aubenque, P. 1976. La prudence chez Aristote. Paris: PUF.

Aubenque, P. 2009. "Amitié et communauté chez Aristote " en La amistad en la filosofía antigua (Zamora Calvo, J. M., ed.). Madrid: Ediciones de la Universidad Autónoma de Madrid, pp. 113-120.

BaliBAR, É. 2010. La proposition de l'égaliberté. Paris: Presses Universitaires de France.

Balibar, É. 2013. Ciudadanía. Buenos Aires: Adriana Hidalgo editora.

BICKFORD, S. 1996. "Beyond Friendship: Aristotle on Conflict, Deliberation and Attention", The Journal of Politics, (58), 2, 398-421.

Blais, M.-C. 2007. La solidarité: histoire d'une idée. Paris: Gallimard.

CAMPS, V. 2012. El gobierno de las emociones. Barcelona : Herder.

De Ste Croix, G. E. M. 1988. La lucha de clases en el mundo griego antiguo. Barcelona: Crítica.

DomèneCH, A. 2004. El eclipse de la fraternidad. Barcelona: Crítica.

FInE, J. V. A. 1983. The Ancient Greeks: A Critical History. Cambridge: Harvard University Press.

Fraisse, J.-C. 1974. Philia: la notion d'amitié dans la philosophie antique: essai sur un problème perdu et retrouvé. París: Lib. Philosophique J. Vrin.

Furet, F y Ozouf, M. 1988. Dictionnaire critique de la Révolution Française. Paris: Flammarion.

Hahm, D. E. 2009. "The Mixed Constitution in Greek Thought" en A Companion to greek and Roman Political Thought (Balot, R. K. ed.). Malden: WileyBlackwell.

Horn, C. 2013. "Law, governance, and political obligation" en The Cambridge Companion to Aristotle's Politics (Deslauriers, M. y Destrée, P. eds.). Cambridge: Cambridge University Press, pp. 223-246.

Kalimitzis, K. 2000. Aristotle on Political Enmity and Disease: an enquiry into stasis. New York: State University of New York Press.

Konstan, D. 1997. Friendship in the Classical World. Cambridge: Cambridge University Press.

LAmbert, S. D. 1998. The Phratries of Attica. Ann Arbor: University of Michigan Press.

Lombardini, J. 2013. "Civic Laughter: Aristotle and the Political Virtue of Humour". Political Theory, 41, (2), 203-230.

Ludwig, P. W. 2009. "Anger, Eros, and Other Political Passions in Ancient Greek Thought", en A Companion to greek and Roman Political Thought. op. cit., pp. 294-307. 
Maquiavelo, N. 1997. El Príncipe. Madrid: Cátedra.

Miller, F. D. Jr. 1991. "Aristotle on Natural Law and Justice" en A Companion to Aristotle's Politics. (Keyt, David y Fred D. Miller, Jr. eds.). Cambridge: Cambridge University Press, pp. 279-306.

Miller, Fred D., Jr. 2001. Nature, Justice, and Rights in Aristotle's Politics. Oxford: Clarendon Press.

Newman, W. L. 1887-1902. The Politics of Aristotle. Oxford: The Clarendon Press.

Pizzolato, L. F. 1996. La idea de la amistad en la antigüedad clásica y cristiana. Barcelona: Muchnik.

Platón. 1981. Diálogos I: Apología, Critón, Eutifrón, Ion, Lisis, Cármides, Hipias Menor, Hipias Mayor, Laques, Protágoras. Madrid: Gredos.

Platón. 2008. Diálogos II: Gorgias, Menéxeno, Eutidemo, Menón, Crátilo. Madrid: Gredos.

Price, A. W. 1990. Love and friendship in Plato and Aristotle. Oxford: Clarendon Press.

RANCIÈRE, J. 2006. El odio de la democracia. Madrid: Amorrortu.

RAVEnTós, D. 2007. Las condiciones materiales de la libertad. Barcelona: El Viejo Topo.

Rawls, J. 1999. A Theory of Justice. Oxford: Oxford University Press.

Rodrígez Adrados, F. 1975. La democracia ateniense. Madrid: Alianza.

Rosenberg, A. 2006. Democracia y lucha de clases en la antigüedad. Barcelona: Viejo Topo.

SchwarzenBaCH, S. A. 1996. “On Civic Friendship”, Ethics, (107), 1, 97-128.

Schwarzenbach, S. A. 2009. On Civic Friendship. Including Women in the State. New York, Columbia University Press.

Zingano, M. 2013. "Natural, ethical, and political justice", en The Cambridge Companion to Aristotle's Politics. op. cit., pp. 199-222.

Oriol Farrés Juste

Universidad Autónoma de Barcelona

oriol.farres@uab.es 